\title{
Measures to Provide Settlements with Quality Drinking Water: Assessment of the Potential by the Example of the Odessa Agglomeration
}

\author{
Oksana Georhiyivna Tserkovna \\ Department of Architectural Space Design, Architectural and Art Institute, \\ Odessa State Academy of Civil Engineering and Architecture, Ukraine \\ E-mail: o.g.tserkovna@gmail.com
}

Published online: 15 December 2021

To cite this article: Oksana Georhiyivna Tserkovna (2021). Measures to provide settlements with quality drinking water: Assessment of the potential by the example of the Odessa agglomeration. Journal of Engineering Science, 17(2), 31-45, https://doi. org/10.21315/jes2021.17.2.3.

To link to this article: https://doi.org/10.21315/jes2021.17.2.3

\begin{abstract}
The rapid urbanisation of the settlements of the Odessa agglomeration has negatively affected the quality of the drinking water that is transported to consumers. The purpose of this study was to determine the most effective measures to provide settlements with quality drinking water. In order to achieve this goal, possible options for measures were considered, and an assessment and comparative analysis of the potential of the proposed options were executed. The most effective measures were evaluated on two criteria: compliance with the principles of sustainable development and whether the measures were effective, reliable and comfortable for consumers when implemented. The factors that influenced the decision-making were the situation and conditions of the implementation of the measures, laboratory tests of the source water and laboratory tests of the water after the treatment process and consumer awareness of participation. The findings demonstrated that a measure was effective if it met the stated criteria. The results of the study are planned to be used as reference material in the elaboration of an integrated plan for the development of settlements, for decision-making in the organisation of recreation and health-related areas and for other resource planning activities.
\end{abstract}

Keywords: quality drinking water, settlements, variants for provision, sustainable development, consumer reliability and comfort

\section{INTRODUCTION}

The rapid urbanisation of settlements has negative consequences for the environment. Unfortunately, it primarily affects the quality of drinking water that is transported to the settlements. In Ukraine, the quality of drinking water transported 
to settlements is regulated by the laws DSanPiN 2.2.4-171-10 ("Hygienic requirements for drinking water intended for human consumption") and DSTU 7525:2014 ("Drinking water: Requirements and methods of quality control"). ${ }^{1,2}$ This paper is devoted to the study of measures that can provide the settlements of the Odessa agglomeration with quality drinking water while complying with the requirements of DSanPiN 2.2.4-171-10 and DSTU 7525:2014.

The quality of drinking water in settlements is primarily determined by the quality of water at the source which are regularly affected by anthropogenic pollution. The main reasons for this type of pollution are as follows:

1. Discharge of untreated or insufficiently treated household and industrial wastewater directly into natural sources through the sewage systems of settlements.

2. Penetration of water from open areas of settlements and agricultural fields into natural sources in the course of the surface flow.

3. Soil erosion in the water intake area.

The main source of drinking water for the Odessa agglomeration (Figure 1a) is the Dniester River [Figure 1b(i)], which annually receives $0.8 \mathrm{~km}^{3}$ to $1.5 \mathrm{~km}^{3}$ of untreated and insufficiently treated wastewater from the territory of Ukraine and Moldova. ${ }^{3}$ Water intake is carried out in the area of Belyaevka village, at a distance of $21 \mathrm{~km}$ upstream, from the influx of the river into the Dniester estuary [Figure $1 \mathrm{~b}(\mathrm{ii})$ ]. Water conditioning of the untreated (river) water to indicators that meet the requirements of DSanPiN 2.2.4-171-10 and DSTU 7525:2014 is performed at the head treatment plant, the Dniester Water Purification Station [Figure $1 b($ iii)], which is located near the village of Belyaevka [Figure 1b(iv)]. At the water purification station (WPS), various water treatment technologies, such as coagulation, sedimentation, filtration and chlorination are applied. Some water conditioning technologies are unsafe. In particular, chlorination not only deteriorates the organoleptic properties of water due to residual amounts of the reagent but also causes the appearance of new toxic substances-products of chemical reactions between the active chlorine and organic impurities.

Currently, the Dniester Water Purification Station cleans and supplies to consumers on average $400 \mathrm{~km}^{3}$ to $550 \mathrm{~km}^{3}$ of water per day, which meets the requirements of DSanPiN 2.2.4-171-10 and DSTU 7525:2014. ${ }^{3-6}$ The water is transported to the settlements of the Odessa agglomeration by a system of water pipelines with diameters of $700 \mathrm{~mm}-1400 \mathrm{~mm}$ and a total length of about 600 $\mathrm{km}$. The disinfection, accumulation and distribution of water in the settlements is provided by a centralised utility and drinking water supply system (CWSS), which 
includes clean water tanks (CWTs), pumping stations (PSs), water distribution networks (WDNs), and others. As a result of prolonged transportation of water through the main pipelines and the unsatisfactory technical condition of the water distribution networks in the settlements, secondary pollution of drinking water occurs due to corroded and leaky water pipes.

1)

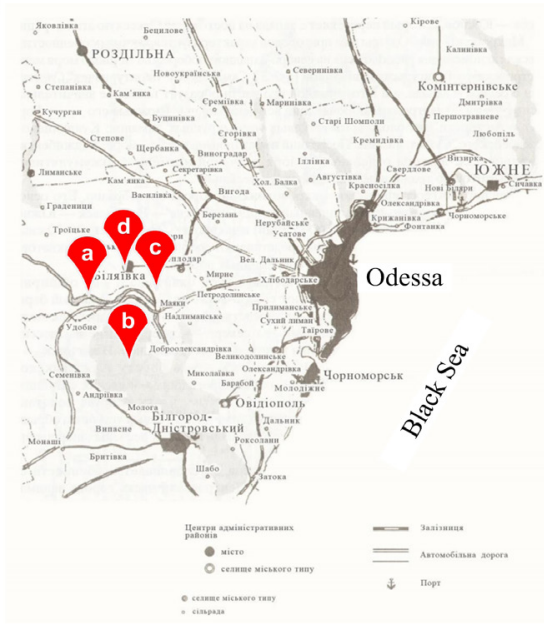

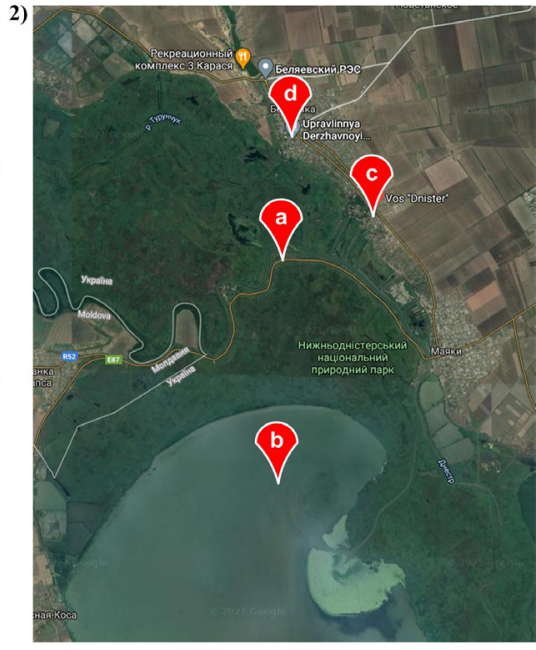

Figure 1: The household water supply of the Odessa agglomeration: (a) Schematic map of the Odessa agglomeration location. ${ }^{3}$ (b) Source of water supply and other significant objects: (i) Dniester River, (ii) Dniester estuary, (iii) Dniester Water Treatment Plant and (iv) Belyaevka settlement.

In order to improve the provision of quality drinking water to the settlements, the emphasis has traditionally been on improving the WPS and CWSS, which almost always ends at a stage of "discussion and decision-making" without fulfilment of the latter. Since the late 1980s, domestic and commercial water treatment facilities (WTFs) and drinking water supply systems (DWSs) in residential buildings were produced and developed in Ukraine, and the production of packaged drinking water was also carried out. ${ }^{4-6}$ A subjective positive assessment of these proposed measures as ways to solve the problems of provision of the settlements with quality drinking water was observed during sociological surveys of consumers and specialists in the water supply field. Unfortunately, there has been a massive flow of low-quality products to the consumer market over the past decade. As a result, proficient advertising companies, multiple publications in periodicals and online media accompanying the entry of such products on the market and represent a certain degree of risk to the health of consumers in the future. For example, a comparative analysis of the results of laboratory studies of drinking water that goes through the process of treatment (as carried out by 
Tserkovna under the leadership of Grabowski ${ }^{6}$ testified that the domestic water treatment facilities (reverse osmosis system) do not provide water that undergoes a water treatment process that achieves an optimal content of mineral components; in other words, the mineral composition does not correspond to the physiological adequacy needed for drinking water (DSanPiN 2.2.4-171-10). ${ }^{1}$ The long-term consumption of water with an imbalance of its main mineral components can be one of the negative factors that affects the health of consumers. The mineral composition of drinking water is not only an indicator of its quality but also an important factor in the development of the health of consumers..$^{6-7}$ Corresponding indicators for comparison are given in Table 1, and a detailed history of the study of water after the water treatment process is discussed in the cited reference. ${ }^{6}$

Table 1: Indicators of physiological usefulness of drinking water mineral composition.

\begin{tabular}{llrc}
\hline Indicator name & Unit of measurement & Standard & Indicators after water treatment process \\
\hline Hardness & $\mathrm{mmol} / \mathrm{dm}^{3}$ & $1.5-7.0$ & 0.05 \\
Magnesium & $\mathrm{mg} / \mathrm{dm}^{3}$ & $10-80$ & 0.4 \\
Alkalinity & $\mathrm{mmol} / \mathrm{dm}^{3}$ & $0.5-6.5$ & 0.25 \\
\hline
\end{tabular}

Measures aimed at the provision of settlements with quality drinking water have been considered by a variety of researchers, such as Solodovnik, ${ }^{4}$ Grabowsky et al. ${ }^{5}$ Tserkovna, ${ }^{6}$ Bartram et al. ${ }^{8}$ Amrose et al., ${ }^{9}$ Styś and Stec, ${ }^{10}$ Gorbanev et al. ${ }^{11}$ and Kumari et al. ${ }^{12}$ Unfortunately, in these studies, the authors did not consider the potential of measures as to compliance with the principles of sustainable development and the efficiency, reliability and comfort for consumers. ${ }^{3-6,8-12}$

In addition, when choosing a measure option, it is important whether the implementation is planned at the pre-design stage, will be implemented in an already existing residential building and/or a complex of residential buildings/ groups or will be carried out in an already formed territory.

In consideration of the above material, the purpose of this study was to determine measures that would effectively provide the settlements of the Odessa agglomeration with quality drinking water while taking into account the specificity of situations and territories where the planned implementation was to occur. Achievement of this goal required the implementation of the following tasks: identify measure options, assess the measures for compliance with the principles of sustainable development and study the features that make the implementation of a particular option the most or least effective, reliable and comfortable for consumers. 
The results of the study will be required as reference material in the elaboration of an integrated plan for the development of settlements, for decisionmaking in the organisation of recreation and health-related areas and for other resource planning activities.

\section{METHODS}

Having reviewed the results of studies presented in the works by Grabowsky et al. ${ }^{5}$ Tserkovna,${ }^{6}$ Safranov et al., ${ }^{7}$ Bartram et al., ${ }^{8}$ Amrose et al., ${ }^{9}$ Słyś and Stec, ${ }^{10}$ Gorbanev et al., ${ }^{11}$ Kumari et al., ${ }^{12}$ Stević-Gojkov, ${ }^{13}$ Rak and Pietrucha-Urbanik, ${ }^{14}$ Delpla et al., ${ }^{15}$ Bain et al. ${ }^{16}$ Parshukov et al., ${ }^{17}$ Hariani et al., ${ }^{18}$ Klamt et al., ${ }^{19}$ Ahsan and Imteaz, ${ }^{20}$ Vinod Kumar and Baskaran ${ }^{21}$ and Kayumov et al., ${ }^{22}$ the methodology was developed, which was based on the methods that were considered and applied by the cited researchers.

In order to clarify the main task and the correct formulation of the definition of "measures to provide settlements with quality drinking water", a comparative analysis of existing regulatory documents were performed..$^{1-2,23}$

\section{FINDINGS AND NOVELTY}

Searching for innovative solutions made it possible to highlight issues that had not been considered earlier:

1. The potential of measures with regard to compliance with the principles of sustainable development.

2. The efficiency, reliability and comfort of the measures for consumers.

3. The specificity of situations or territories where the measures were to be implemented to provide settlements with quality drinking water.

The author has developed and proposed a methodology that will allow factors that subsequently affect the implementation and development of the measure to be taken into account.

The assessment of potential includes an analysis of a variety of solutions that will increase the effectiveness of a measure and its reliability and comfort over the long term. The assessment also includes how the measure will contribute to lower implementation costs, which are extremely important in providing a rationale regarding the use of available resources and compliance with modern principles of sustainable development. 


\section{RESULTS}

The measures to provide settlements with quality water are a complex set of technical solutions. The results of which are aimed at the implementation of the main task: the reliable and comfortable provision of consumers of the settlements with quality drinking water. ${ }^{1-2,22}$ The water quality must comply with the requirements of DSanPiN 2.2.4-171-10 and DSTU 7525:2014, and the optimal content of mineral components in the water shall correspond to the physiological adequacy of drinking water. ${ }^{7}$

Consolidation of complex technical solutions into a whole (measure) is quite challenging. The source water quality and the situation in the territory where the measure is to be implemented are crucial in the decision-making process. These two factors ultimately determine the financial (economic) component of the planned measure. One of the significant financial components is the selection of the technical equipment for the implementation of the measures. ${ }^{4-6,8-11}$

Consider the main recommended measures to provide the settlements of the Odessa agglomeration with quality drinking water:

1. Reconstruction of the head treatment facilities at the Dniester Water Purification Station and CWSS (Figure 2a).

2. Provision of bottled water (Figure $2 b$ ).

3. Installation of water sales points (Figure 2c).

4. Installation of purified water machines (Figure 2d).

5. Increase in the promotion of domestic WTFs (Figure 2e).

6. Installation of DWSs in residential buildings and/or a complex of residential buildings/groups (Figure 2f).

We make a comparative analysis of the potential of the proposed variants while taking into account the specificity of situations or territories where the measures are expected to be implemented to provide settlements with quality drinking water.

According to previous studies, the potential of a measure such as the reconstruction of head treatment facilities was assessed as low. ${ }^{4-6}$ The main disadvantage of this considered option is that according to observations, a consumer needs $3 \mathrm{~L}$ to $5 \mathrm{~L}$ of drinking water per day, and the Dniester Water Purification Station transports $550 \mathrm{~km}^{3}$ of drinking water per day to the settlements of the Odessa agglomeration. The amount of water supply needed per individual 
was determined by the established standard of drinking water consumption, which regulates the amount of drinking water necessary to meet the drinking, physiological, sanitary and hygienic and domestic needs of one consumer during the day in a particular settlement with normal operation of the centralised utility and drinking water supply systems and in case of their failure. The current maximum specific average (over a year) daily consumption rate of drinking water in Ukraine is $285 \mathrm{~L} /$ day per inhabitant (DBN B.2.5-74:2013, as shown in Table 1), ${ }^{23}$ which significantly exceeds the amount required of individuals. The studies conducted by Safranov et al. ${ }^{7}$ and Guseva ${ }^{3}$ demonstrated that the water treatment process technologies provided by the Dniester Water Purification Station are adequate and most appropriate in the prevailing circumstances. ${ }^{3,7}$ Consequently, the option of reconstruction of the head treatment facilities will not be further considered, and the process of updating and modernisation of the centralised utility and drinking water supply system should be considered a normal ongoing need.

a)

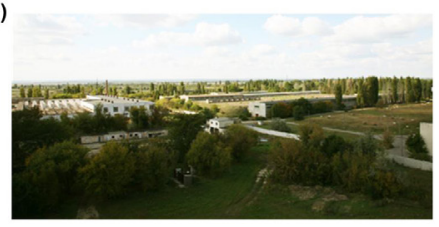

d)

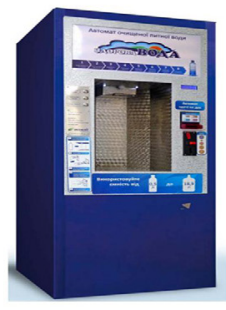

b)

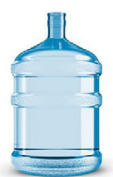

e)

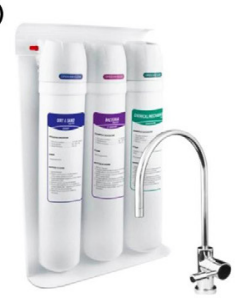

c)

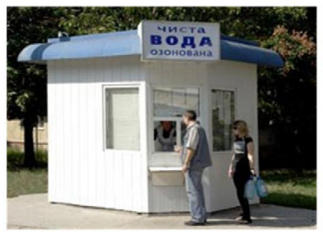

f)

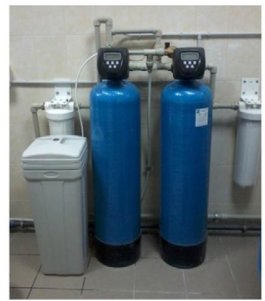

Figure 2: Examples of measures to provide the settlements with quality drinking water: (a) Dniester Water Purification Station, (b) bottled water, (c) water sales points, (d) purified water machines, (e) domestic water treatment plants and (f) drinking water supply systems in residential buildings and/or a complex of residential buildings.

The measure to provide the settlements with bottled water also has a low potential for implementation, as it has a number of major deficiencies. ${ }^{5-6,24}$ This is primarily caused by the additional costs of producing plastic containers for transportation and storage as well as the costs for sale, transportation and distribution of the bottled water in settlements. Bottled water distribution by in road transport will increase greenhouse gas emissions into the atmospheric air. 
In addition, there is a significant expenditure of human resources for the delivery of water to the consumer in the course of the implementation of the measure. Unfortunately, previous studies did not consider the environmental component of options for providing settlements with quality drinking water. ${ }^{4-6}$

Having calculated and compared the operating costs of the considered options, Grabowsky et al. ${ }^{5}$ came to the conclusion that the provision of bottled water as an option was not economically viable because the cost of the measure was high and the implementation was not rational. Tserkovna ${ }^{6}$ assessed measures by criteria such as sanitary, reliability and comfort for consumers. In her study, the bottled water supply option received the highest rating in terms of sanitary and reliability but was the lowest in terms of comfort.

In analysing the presented material, it can be affirmed that the potential of the provision of bottled water measure is low, because it does not meet modern principles of sustainable development (environmental, economic and social) and requires significant human resources for implementation.

We paid attention to the measures that were maximally adapted to the implementation on the territory of settlements of the Odessa agglomeration and were consistent with modern principles of sustainable development. ${ }^{13,14,20-22}$

The analysis of the technical equipment installed in water sales points, purified water machines and main devices (cores) of drinking water supply systems in residential buildings demonstrated that the equipment used is identical and in fact constitutes a commercial water treatment facility. ${ }^{6,10,20-22}$

Water treatment facilities for domestic and commercial purposes are modular systems with equipment compositions based on modern principles of sustainable development - efficiency, environmental friendliness and social need - that take into account the marketing of the equipment and its operational experience. ${ }^{20-22}$ Modular design makes it possible to individually select water treatment facility equipment for water sales points, purified water machines and drinking water supply systems in residential buildings based on a laboratory study of the source (tap) water for the residential building and/or a complex of residential buildings/groups of buildings. A domestic water treatment facility also allows one to select equipment for each apartment individually. ${ }^{6}$ The main task of domestic and commercial water treatment facilities is the conditioning of the tap water, that is, bringing the quality of tap water up to the requirements of standards, such as DSanPiN 2.2.4-171-10 and DSTU 7525:2014. ${ }^{1-2}$ 
The prerequisites that should be considered when choosing variants of domestic and commercial water treatment facilities are energy efficiency, relevance (use of innovative components), a proper degree of automation and independence, reliability, comfort, technical feasibility and appropriateness (taking into account the full cycle of operation of the engineering systems and all associated costs) and ergonomics. ${ }^{6,12,20-22}$

The assessment of the potential of measures to provide settlements with quality water is based on a methodology for the analysis of the life cycle cost of water supply systems ${ }^{22}$ In general, an assessment of the potential of a measure can be described by the following equation:

$$
M P=C C+O C
$$

where $M P$ is the cost of the measure potential, $C C$ are the initial capital costs $(C C)$ and $O C$ are the annual operating costs.

The initial CC are defined as follows:

$$
C C=P E+P A+E I+P C
$$

where $P E$ are costs for the purchase of equipment, $P A$ are costs for the purchase of associated accessories, $E I$ are costs for equipment installation and $P C$ is the purchase of commissioning.

The OC are defined as follows:

$$
O C=C W+C E+S M+P P+C L+D C
$$

where $C W$ is the cost of (tap) water, $C E$ is the cost of electricity that supports the operation of the measure, $S M$ is the cost of service or sanitary-engineering maintenance, $P P$ is the cost of replacement of quick-wearing parts, $C L$ are the costs of liquidation and disposal and $D C$ are the depreciation charges. The depreciation is calculated according to the following formula:

$$
D C=C C / T
$$

where $C C$ is the initial capital costs (Eq. 2) and $T$ is the design life. 
Analysis of the studies made it possible to highlight the specificity of the situations that make one or another measure option the most or least effective, reliable and comfortable. The result of the measure potential study is presented in Figure 3.

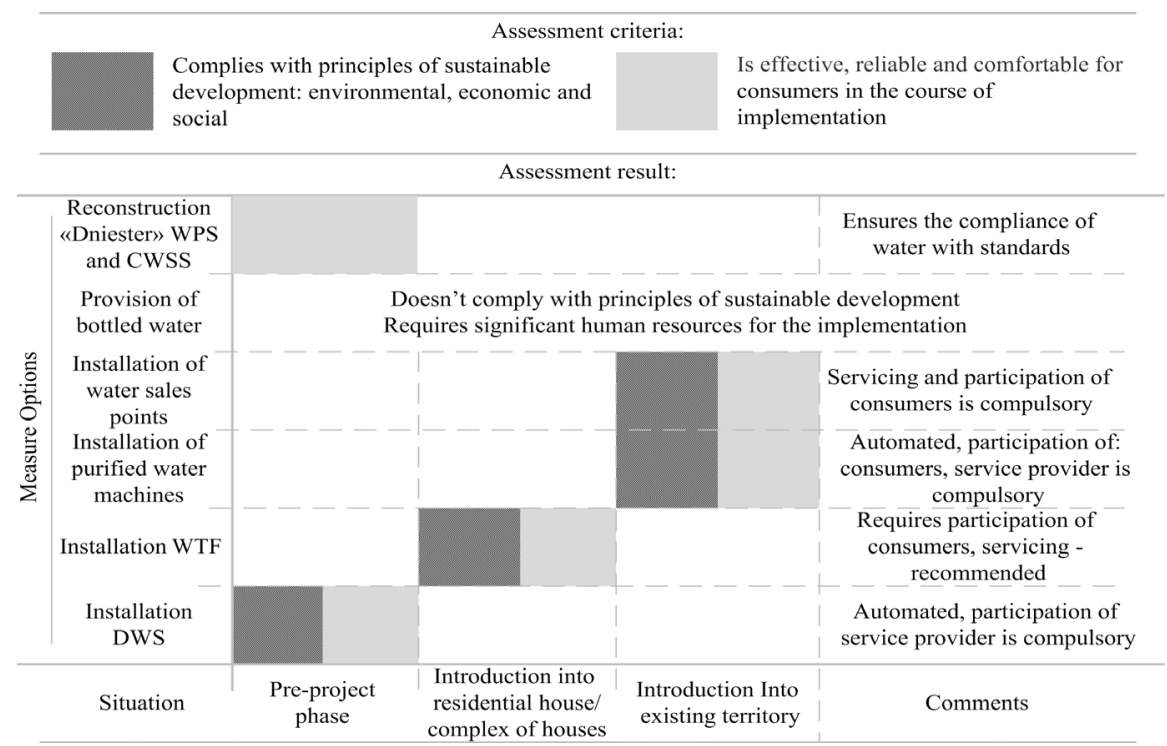

Figure 3: Study of the measures' potentials: for compliance with the principles of sustainable development; for efficiency, reliability and the comfort of consumers.

\section{DISCUSSION}

An analytical study was conducted to determine options of measures to provide quality drinking water to consumers in the settlements of the Odessa agglomeration. The assessment and comparative analysis of the potential for each of the proposed options was made taking into account the specificity of the situations or territories where the measures were expected to be implemented. This made it possible to highlight the most effective options.

The most effective measures were assessed based on two criteria: compliance with the principles of sustainable development and the efficiency, reliability and comfort of the consumers.

A number of factors were identified that influenced the decision-making. The situation or conditions of implementation of the measures (such as automation 
or servicing required, participation of consumers, service provider, etc.) were examined for each. Laboratory tests of the source water and of the water after the treatment process were the grounds for the selection of technical equipment that ensured the correct implementation of a measure. Lastly, whether consumer awareness of participation increased the effectiveness of a measure in the course of implementation and operation was considered.

It is also worth noting that in recreation areas and historical and cultural centres of the settlements, one of the most comfortable measures to provide the population with quality drinking water is the installation of purified water machines and water sales points. Water sales are planned to be carried out with consumer's containers and proposed containers of various volumes. For the integrated inclusion of the measures in the surrounding space of the settlements, attention should be paid to the external design. The organisation of measures in the proposed way and in the proposed zones will increase the comfort of the open areas of the settlements that are intended for walking, group activities and passive recreation; these areas also allow social communication with the consumers. Implementation of these measure options will be the most effective and the most in-demand during hot, dry weather conditions.

In view of the above, measures to provide quality drinking water to consumers should be taken into consideration when designing an integrated development plan for the settlements of the Odessa agglomeration. It should contain specific parameters for the development of the recreation zones and areas for health improvement purposes (impact), and it is necessary to plan the resource support for the implementation of the intended measures for portions of the settlement territories.

The considered measure options to provide quality drinking water to the consumers in the settlements should be implemented and can successfully coexist, complimenting each other. In addition, following the described material, empirical research has confirmed the interconnection between awareness and consumer trust. The research methodology can be applied to other agglomerations with similar resource provisions.

One limitation of this study is that it focused on providing good options for consumers but did not address the reduction of existing poor options. Unfortunately, in the context of this issue, how to reduce the mass flow of low-quality products on the market has not been studied. This remains a challenge to the health of consumers and a waste of their resources. 


\section{CONCLUSION}

Having reviewed options for providing the settlements of the Odessa agglomeration with quality drinking water, the following conclusions were made: a measure is effective if it complies with the principles of sustainable development (environmental, economic and social) and, in the course of implementation, if it is effective, reliable and comfortable for consumers.

The results of the study will be used as reference material in the elaboration of an integrated plan for the development of settlements, for decision-making in the organisation of recreation and health-related areas and for resource planning activities.

\section{ACKNOWLEDGEMENTS}

This article was based on a number of studies that were previously conducted out of the Department of Water Supply, Institute of Hydraulic Engineering and Civil Engineering, Odessa State Academy of Civil Engineering and Architecture (Ukraine), under the supervision of D.Sc. in Engineering, Professor P. Grabowsky (1941-2018). The author is grateful to Professor P. Grabowsky as a mentor and advisor for his patience, valuable supervision and acquired original knowledge in the field of water treatment technologies.

\section{REFERENCES}

1. Гігієнічні вимоги до води питної, призначеної для споживання людиною (Hygienic requirements for drinking water intended for human consumption), DSanPiN 2.2.4-171-10 [in Ukrainian] (2010). Retrieved from https://zakon.rada.gov.ua/laws/show/z0452-10.

2. Питна вода. Вимоги та методи контролю якості (Drinking water. Requirements and methods of quality control), DSTU 7525:2014 [in Ukrainian] (2014). Retrieved from, http://iccwc.org.ua/docs/ dstu_7525_2014.pdf.

3. Guseva, K. (2018). The condition and quality of the environment of urbanized areas (by an example of the city of Odessa) [in Ukrainian]. PhD diss., Odessa State Environmental University, Ukraine. 
4. Solodovnik, M. (2007). Assessment of the economic efficiency of variants for improving the quality of drinking water in Kharkiv [in Russian]. Municipal Economy of the Cities, 74, 289-294. Retrieved from https:// khg.kname.edu.ua/index.php/khg/article/view/3185.

5. Grabowsky, P., Larkina, G. \& Progul'nyy, V. (2015). Quality drinking water for the population [in Russian]. In Problems of water supply and hydraulic engineering [in Russian]. Scientific and Technical Collection, 25, Kyiv, Ukraine: Kyiv National University of Construction and Architecture, 69-75. Retrieved from http://ibrary.knuba.edu.ua/books/ zbirniki/17/201525.pdf.

6. Tserkovna, O. (2014). Drinking water supply system in residential buildings [in Russian]. Masters diss., Odessa State Academy of Civil Engineering and Architecture, Ukraine.

7. Safranov, T., Polishchuk, A., Yurchenko, V. \& Yarishkina, L. (2016). Assessment of the optimality of drinking water mineral composition in the centralized water supply systems of some urban agglomerations of Ukraine [in Ukrainian]. Вісник Харківського національного університету імені В. Н. Каразіна Серія : Екологія, 15, 89-98. Retrieved from http://nbuv. gov.ua/UJRN/VKhNU_2016_15_14.

8. Bartram J., Brocklehurst, C., Fisher, M., Luyendijk, R., Hossain,R., Wardlaw, T. \& Gordon B. (2014). Global monitoring of water supply and sanitation: History, methods and future challenges. Int. J. Environ. Res. Public Health, 11(8), 8137-8165, https://doi.org/10.3390/ ijerph110808137.

9. Amrose, S., Burt, Z. \& Ray, I. (2015). Safe drinking water for low-income regions. Annu. Rev. Environ. Resour., 40(1), 203-231, https://www. annualreviews.org/doi/abs/10.1146/annurev-environ-031411-091819.

10. Słyś, D. \& Stec, A. (2015). The analysis of variants of water supply systems in multi-family residential building. Ecol. Chem. Eng. S., 21(4), 623-635, https://doi.org/10.1515/eces-2014-0045.

11. Gorbanev, S., Novikova, Y., Kovshov, A., Tikhonova, N. \& Fedorov, V. (2020). Problems of providing Russian Arctic population with high quality drinking water. IOP Conf. Ser. Earth Environ. Sci., 539(1), https:// doi.org/10.1088/1755-1315/539/1/012104.

12. Kumari, C. U., Lydia. E. L., Murthy, A. S. D. \& Kumar, M. N. V. S. S. (2020). Designing of wireless sensor nodes for providing good quality drinking water to the public. Mater. Today: Proc., 33, 4250-4254, https:// doi.org/10.1016/j.matpr.2020.07.352.

13. Stević-Gojkov, Z. (2018). Equal access to the feasibility of the right to safe and quality drinking water: Indicator of sustainable development. Tehnika, 73(4), 594-599. 
14. Rak, J. \& Pietrucha-Urbanik, K. (2019). An approach to determine risk indices for drinking water: Study investigation. Sustainability, 11(11), 3189, https://doi.org/10.3390/su11113189.

15. Delpla, I., Proulx, F. \& Rodríguez, M. J. (2020). A methodology to prioritize spatio-temporal monitoring of drinking water quality considering population vulnerability, J. Environ. Manage., 255, 109869, https://doi. org/10.1016/j.jenvman.2019.109869.

16. Bain, R., Johnston, R. \& Slaymaker, T. (2020). Drinking water quality and the SDGs. NPJ Clean Water, 3, 37, https://doi.org/10.1038/s41545-02000085-z.

17. Parshukov, D., Shaporova, Z. \& Koloskova, I. (2020). Statistical metrics for providing the population with drinking water of standard quality. J. Phys. Conf. Ser., 1515, 052081, https://doi.org/10.1088/17426596/1515/5/052081.

18. Hariani, B. et al. (2021). The assessment of the quality of water from regional drinking water company Giri Menang as a source of community drinking water in the City of Mataram. J. Biol. Tropis, 21(1), 120-130, http://dx.doi.org/10.29303/jbt.v21i1.2209.

19. Klamt, R., Ben da Costa, A., Gaedke, M. \& Lobo, E. (2021). Drinking water quality indices: A systematic review. Rev. Ambient. Água, 16(2), 1-14, http://dx.doi.org/10.4136/ambi-agua.2630.

20. Ahsan, A. \& Imteaz, M. (2019). Nanofiltration membrane technology providing quality drinking water. In A. Ahsan \& A. F. Ismail (eds.), Micro and nano technologies, nanotechnology in water and wastewater treatment. Amsterdam: Elsevier, 291-295, https://doi.org/10.1016/B9780-12-813902-8.00014-9.

21. Kumar, S. V. \& Baskaran, R. (2020). Novel integrated ultrafiltration and reverse osmosis system in high quality drinking water production. Orient. J. Chem., 36(6), 1243-1247, http://dx.doi.org/10.13005/ojc/360634.

22. Kayumov, I., Nurullin, Z. H., Nizamova, A. \& Sheshegova, I. (2016). Improvement of reliability and efficiency of water supply and water disposal systems [in Russian]. Фундаментальные исследования., 12(5), 985-988. Retrieved from http:/www.fundamental-research.ru/ru/article/ view?id=41203. 
23. Водопостачання. Зовнішні мережі та споруди (Water supply. External networks and construction), DBN B.2.5-74:2013 [in Ukrainian] (2013). Retrieved from https://polyplastic.ua/files/DSTU/dbn_v.2.5_74_2013. pdf.

24. Strikalenko, T. V. (2012). Bottled water quality rationing: A step forward or two steps back? [in Russian]. In Collected reports of international congress «ETEVK-2011». Yala, Ukraine: ETEVK-2011. Retrieved from http://www.etevk.org.ua/Res/zbir.pdf. 